\title{
Techniques for improving the water-flooding of oil fields during the high water-cut stage
}

\author{
Kuiqian $\mathrm{Ma}^{1}$, Ao $\mathrm{Li}^{2}{ }^{*}$, Shuhao Guo ${ }^{2}$, Jieqiong $\mathrm{Pang}^{2}$, Yongchao Xue ${ }^{2}$, and Zhonghao Zhou ${ }^{2}$ \\ ${ }^{1}$ Tianjin Branch of CNOOC Limited, Tianjin 300459, PR China \\ ${ }^{2}$ State Key Laboratory of Petroleum Resources and Prospecting in China University of Petroleum, Beijing 102249, PR China
}

Received: 25 July 2018 / Accepted: 15 July 2019

\begin{abstract}
The multi-layer co-exploitation method is often used in offshore oilfields because of the large spacing between the injection and production wells. As oilfields gradually enter the high water-cut stage, the contradiction between the horizontal and vertical directions becomes more prominent, and the distribution of the remaining oil is more complex. Oilfields are facing unprecedented challenges in further enhancing oil recovery. Using oilfield A, which is in the high water-cut stage, as the research object, we compiled a detailed description of the remaining oil during the high water-cut stage using the information collected during the comprehensive adjustment and infilling of the oilfield. In addition various techniques for tapping the potential reservoir, stabilizing the oil, and controlling the water were investigated. A set of key techniques for the continuous improvement of the efficiency of water injection after comprehensive adjustment of high water-cut fields was generated. Based on the determined configuration of the offshore deltaic reservoir, a set of detailed descriptive methods and tapping technology for extracting the remaining oil in the offshore high water-cut oilfield after comprehensive adjustment was established. By considering the equilibrium displacement and using a new quantitative characterization method that includes displacement, a new technique for determining the quantity of water that needs to be injected into a stratified injection well during the high water-cut stage was established. Based on the principle of flow field intensity reconfiguration, a linear, variable-intensity, alternating injection and withdrawal technique was proposed. With the application of this series of techniques, the increase in the water content was controlled to within $1 \%$, the natural reduction rate was controlled to within $9 \%$, and the production increased by $1.060 \times 10^{7} \mathrm{~m}^{3}$.
\end{abstract}

\section{Introduction}

Oilfield A, a large-scale complex oilfield in an offshore delta with high porosity, high permeability, and strong heterogeneity, was put into operation in 1993. This field has now entered the high water-cut stage. As the oilfield drilling progresses deeper, a series of problems such as the poor driving of water and prominent conflicts between planes, layers, and interlayers have gradually been exposed [1]. At the end of 2009, a large-scale offshore comprehensive adjustment project was implemented, and the production of the oilfield was significantly improved [2, 3]. However, after the oilfield entered the high water-cut stage and this development was implemented, the distribution of the remaining oil became increasingly complex, exhibiting overall decentralization and local enrichment characteristics. The development of oilfields has revealed prominent problems such as exacerbated water channeling, increased descent, and increasing

\footnotetext{
* Corresponding author: 737855637@qq. com
}

difficulty in tapping the potential oil reserves. Therefore, it is imperative that we explore a set of effective techniques for implementation in offshore high water-cut oilfields that have undergone comprehensive adjustment to improve the water injection efficiency and apply these techniques to oilfield development.

The distribution of the remaining oil is mainly affected by the micro-effects of reservoir heterogeneity and fluid gravity as well as the macroscopic influence of the development method used, which determines the seepage characteristics of the fluid in the initial stage of oilfield development. Gladkov et al. established a Capacity-Resistance Model (CRM) by matching production and injection data. The oil-water production fracture and the remaining reserves are calculated per reservoir unit. The results were validated with history matched streamline and conventional simulation models [4]. Zhao et al. used the Semi-Supervised Learning (SSL) method to classify the remaining oil in the high water-cut period based on the database obtained from 2D experiments on an etched glass micro-model [5]. Li et al. conducted a reservoir architecture analysis of the delta front 
based on the core, seismic data, dense well logging data, and performance data [6]. Roueché and Karacan identified the residual oil zone and assessed the remaining oil using the probabilistic and predictive methods. Unfortunately, these techniques do not take into account the geological characteristics of the reservoir, such as interlayers and the contact relationship of the planar configuration units [7].

In addition, there are many methods of improving the oil production of reservoirs by evaluating and optimizing the water injection efficiency. The CRM can characterize the dynamic connectivity of the injection and production wells in the reservoir, and it can analyze the influence of the injection and production imbalance on the liquid production [8-10]. In order to optimize water-flooding of sandstone reservoirs, $\mathrm{Lu}$ and $\mathrm{Xu}$ summarized several sophisticated approaches, including zonal water injection, changing the direction of the fluid flow, subdividing the injection-production unit, water shut-off to improve the areal sweeping efficiency, and cyclic water injection [11]. These techniques are particularly applicable to multi-layer heterogeneous reservoirs in the high water-cut production stage. However, we still need to determine how these methods can be applied to offshore oil.

In addition, in order to accelerate water channeling and increase diminishment in the high water-cut stage, the general principle of "combining point and surface, focusing on both injection and production" is proposed as a technique to "stabilize the oil production rate and control the water cutting." The detailed configuration of the reservoir, the optimization of the stratified water injection, and the control of the intensity of the in-plane injection and production were used as technical measures to ensure the long-term, high-yield, stable production of high water-cut oilfields. Figure 1 shows a flow chart of the improvement of this series of techniques.

\section{Detailed description of residual oil based on reservoir configuration research}

Both domestic and international research on the reservoir configurations of continental oilfields have primarily depended on highly concentrated well patterns and coring test data. However, the investigation of the reservoir configurations of offshore oil fields with large well spacing (350$400 \mathrm{~m}$ ) and less coring test data is more difficult [12, 13]. In order to gain a detailed understanding of and a technique for tapping the remaining oil in high water-cut oilfields and to make full use of the data on the large-scale infilling adjustments in the high water-cut stage, in this study, a new reservoir configuration is proposed. This configuration involves using the seismic, horizontal well, and logging interpretation data for water injection along with dissection research methods [14]. We conclude that the interphase interference as well as the interlayer and contact relationships of the planar configuration unit are the main factors controlling the distribution of the residual oil in the high water-cut stage. Based on these results, the tapping of the potential residual oil was also studied [15].

\subsection{Detailed description of the remaining oil based on reservoir configuration studies}

\subsubsection{Research principles and methods for offshore reservoir configurations in a delta front}

Based on the sequence stratigraphy, the division and comparison of the different reservoir levels were carried out using cycle division and level analysis methods. Simulation of the sedimentary evolution, seismic two-dimensional forward modeling, and other techniques were used to determine the pattern of the sedimentary layers of reservoir sandstone. The technical methods used to determine the boundary of the isochronous strata are based on a deltaic sedimentary structural model. This model identifies the gyration interface based on well logging curves and determines the sedimentary units corresponding to the sequence units based on the seismic phases and deltaic sedimentary structures. Based on the general characteristics of the superimposed patterns and log curves of the sedimentary cycle of the delta, the sedimentary cycles of the deltaic sedimentary cycles in the first phase of the profile were further divided into several sub-level sedimentary cycles. Based on the analytic hierarchy process, the sedimentary succession of the complex sand bodies was further divided into a number of subcycles, i.e., single sand bodies were identified based on the general characteristics of the superimposed patterns and the log curves of the sedimentary cycles of the composite sand bodies.

1. Identification methods and characterization techniques of the configuration interface.

Fine-grained sediments, such as silty mudstone, mudstone, and calcareous sandstone formed by diagenesis, are distributed above and below the structural interface at different levels and form barrier-interlayers. The development of the barrier-interlayer is closely related to the development of the configuration. The horizontal seepage between the isochronous layers forms the barrier layer, while the diagonal seepage between the sand bodies of a single estuary bar forms the interlayer. The discontinuous interlayers serve as either an impermeable barrier or a barrier with ultralow permeability to fluid flow, and thus, they have a significant impact on the injection process.

Based on the large well spacing of offshore oilfields and the sedimentary characteristics of deltaic reservoirs, calibration of the coring lithology of coring wells was conducted first. Based on the principle of hierarchical structural relationships, the barrier-interlayers in the study area were divided into three levels, corresponding to levels $3-5$ of the configuration interface (Fig. 2). Then, logging response templates for the different levels of the interlayer in the study area were established. By using these well logging response templates, single-well interlayer identification of the remaining non-coring wells in the study area was conducted to identify and characterize the interfaces of the different levels of the offshore deltaic reservoir.

\section{Characterization of the four-level configuration unit.}

The corresponding phase units of the four-level configuration units are generally the distributary channel 


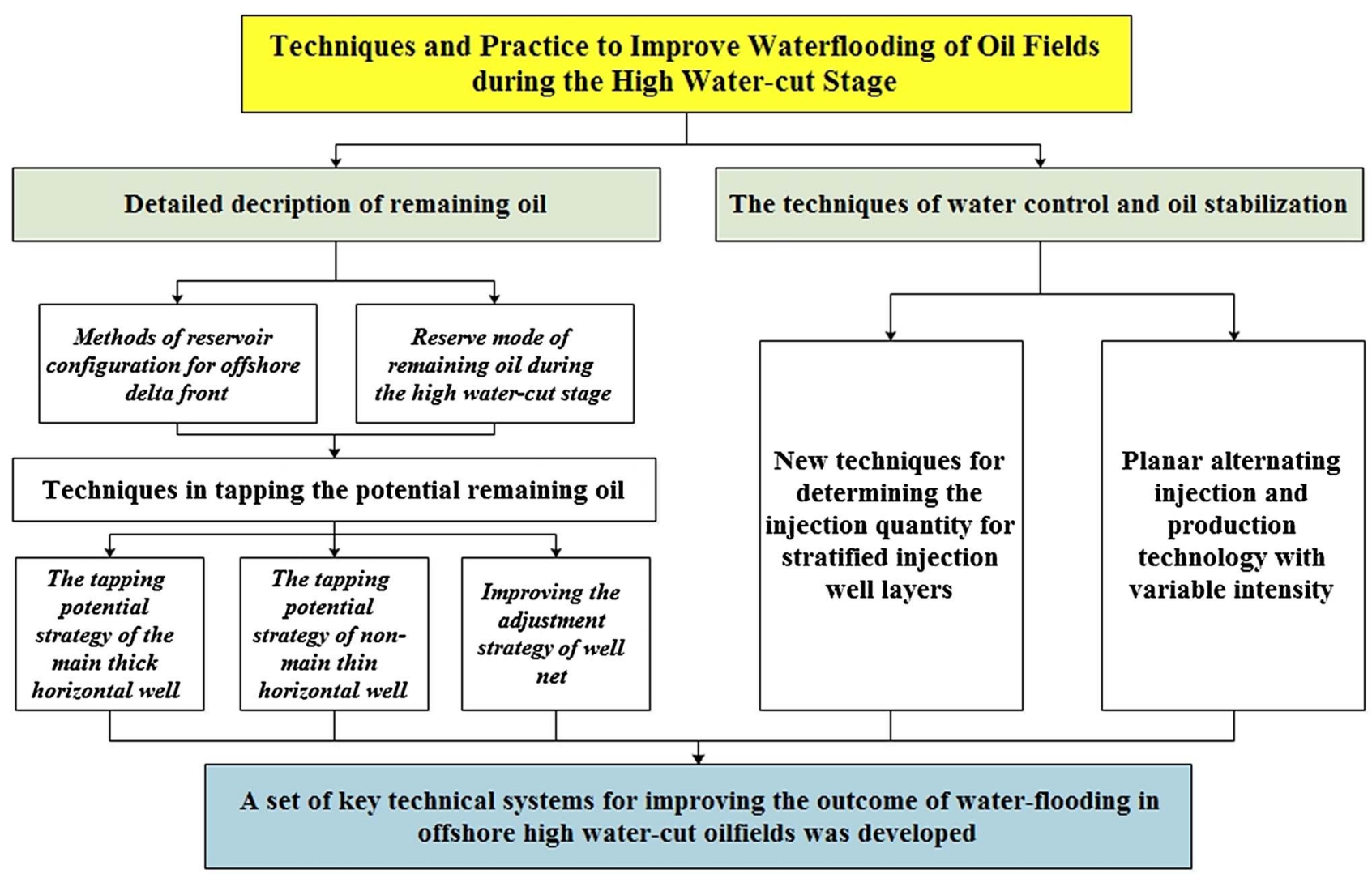

Fig. 1. Flow chart for improving development.

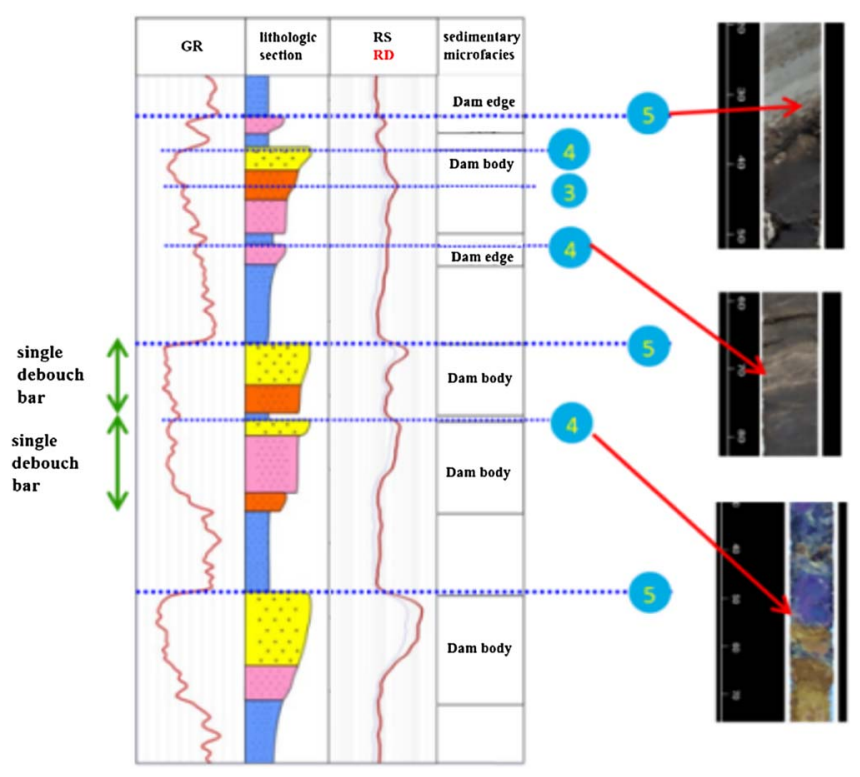

Fig. 2. Identification of the different levels of the configuration interface.

of a single underwater channel and deposition of a single mouth bar. The anatomical method primarily uses the principle of the analytical hierarchy process. First, based on identification of the configurational interface, we analyzed single-well facies using petroclival calibration, and then, we subdivided the composite microfacies into individual microfacies. Then, the single micro phases were characterized longitudinally based on the sedimentary characteristics of the distributary channel of the delta front submarine facies and the mouth bar.

3. Three-dimensional characterization of the multidimensional interaction and sub-facies distribution within the configuration unit.

Based on the distribution and anatomy of the microfacies of the single layer sand body in oilfield A, the distribution of the interlayers at all levels was characterized. These results suggest that the muddy interior of the mouth bar behaves in differently in the directions tangent to and parallel to the provenance direction. In the direction parallel to the provenance direction, the interlayer developed toward the mouth of the channel. The occurrence of the interlayer is closely related to the development of the mouth bar. Generally speaking, the greater the extent to which the underwater distributary channels "stretch" forward, the steeper the dip of the pre-product intercalations. In the direction tangent to the provenance, the mouth bar tends to be vertically superimposed, and the interlayer is symmetrically distributed on both sides of the channel. Therefore, the muddy interlayers tend to be arched (Fig. 3). 


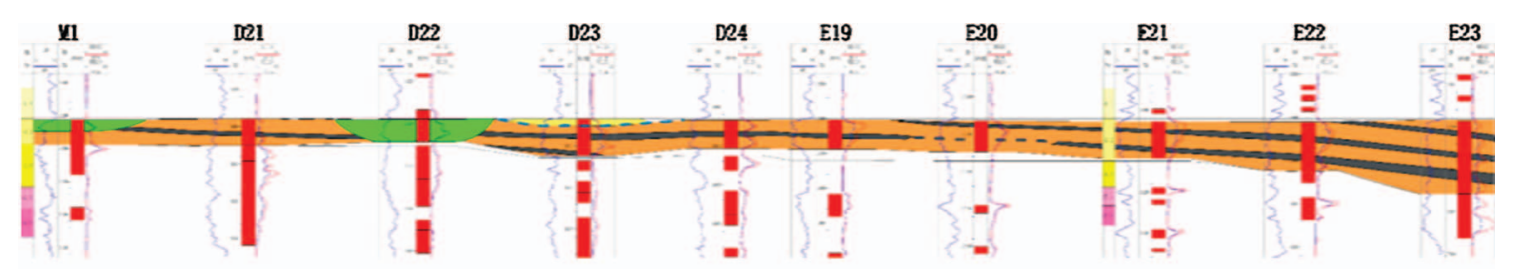

(a) Forward interlayer parallel to the provenance direction

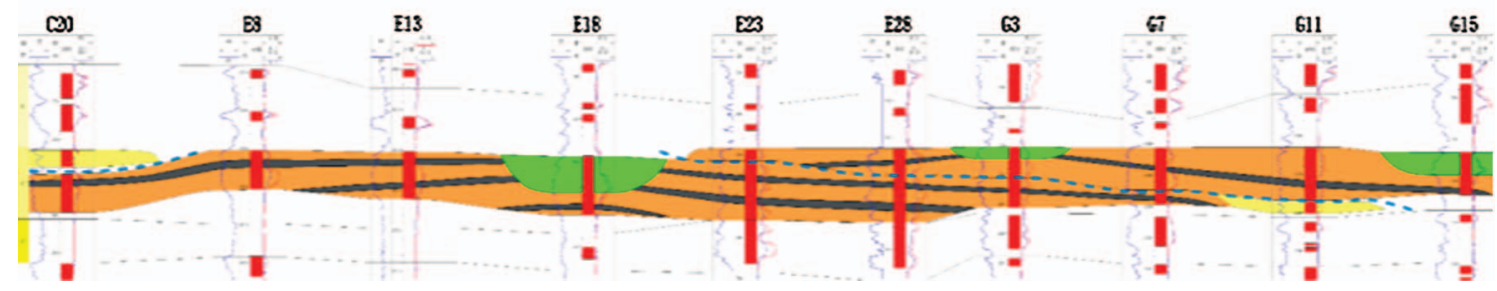

(b) Arched interlayer tangent to the provenance direction.

Fig. 3. Anatomy of the interlayer within a single mouth bar. (a) Forward interlayer parallel to the provenance direction, (b) arched interlayer tangent to the provenance direction.

4. Summary of the three-dimensional configuration pattern.

After the detailed dissection of the individual microassemblage patterns and their quantitative scales at different levels in the study area and the identification of the distribution characteristics of the individual micro-phase units and the spatial distribution patterns of the interior interlayers within the mouth bar, the spatial distribution patterns of the sedimentary microfacies in the study area were established by combining the vertical evolution characteristics of the sedimentary microfacies in the study area.

The mouth bar was the main structural element within the delta front. The distributary channel developed above the mouth bar, and a small number of beach dams

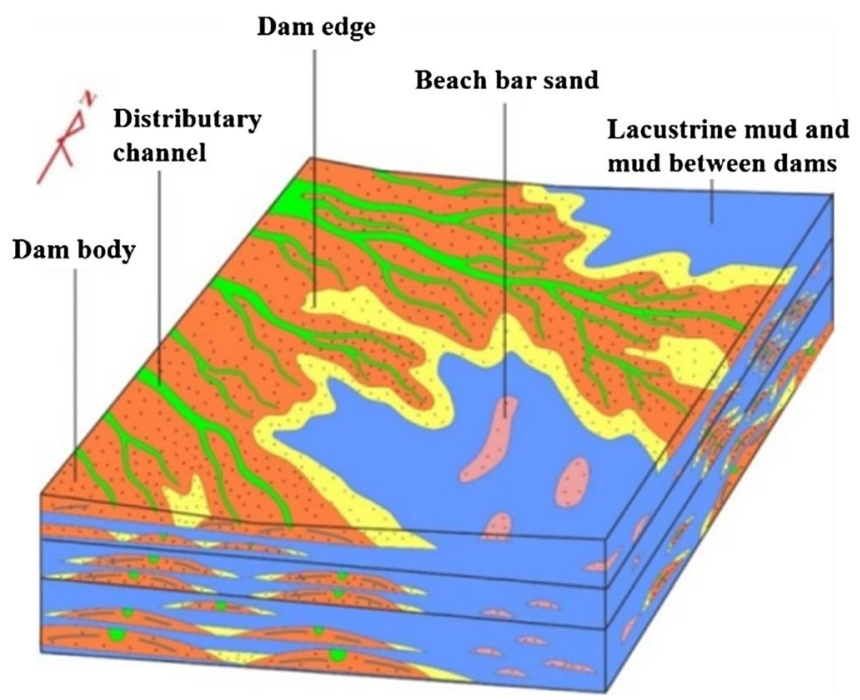

Fig. 4. 3D configuration of the deltaic front. developed in front of the delta front. There were various superimposition patterns within each single layer sandbody in the vertical direction, indicating forward superimposition, backward superimposition, and additive superimposition. The mouth bar sandbody within a single layer primarily presented as a long-tailed shape, while the laterally stacked sandbodies presented as a wide band or even as flake shaped. Distributary channels were generally smaller scale branched strips (Fig. 4). Since the forward superimposed interlayer developed within the mouth bar sand bodies and the migration effect of the distributary channel was weak, the upper arched interlayer formed perpendicular to the provenance direction (Fig. 5).

\subsubsection{Reserve of the remaining oil in the deltaic reservoirs of oilfield $A$ during the high water-cut stage}

After the oilfield entered the high water-cut stage, the contradictions in development were gradually exposed. Because oilfield A is a long-term co-mining, large-scale, integrated heavy oilfield, the three contradictions were controlled by the complex internal structural features of the deltaic facies. Based on the fine dissection of the reservoir's configuration and the infilling information from the wells, the contact relationship between the injection and production units of each of the past configuration units was clarified. The controlling factors and the occurrence of the remaining oil after the oilfield entered the high water-cut stage were summarized with respect to the following three major aspects (Fig. 6):

1. The remaining oil in the plane was mainly controlled by the horizontal injection-production contact relationship between the different configuration units. When the injection well was located in the main configuration unit (river, dam body), the injection and 


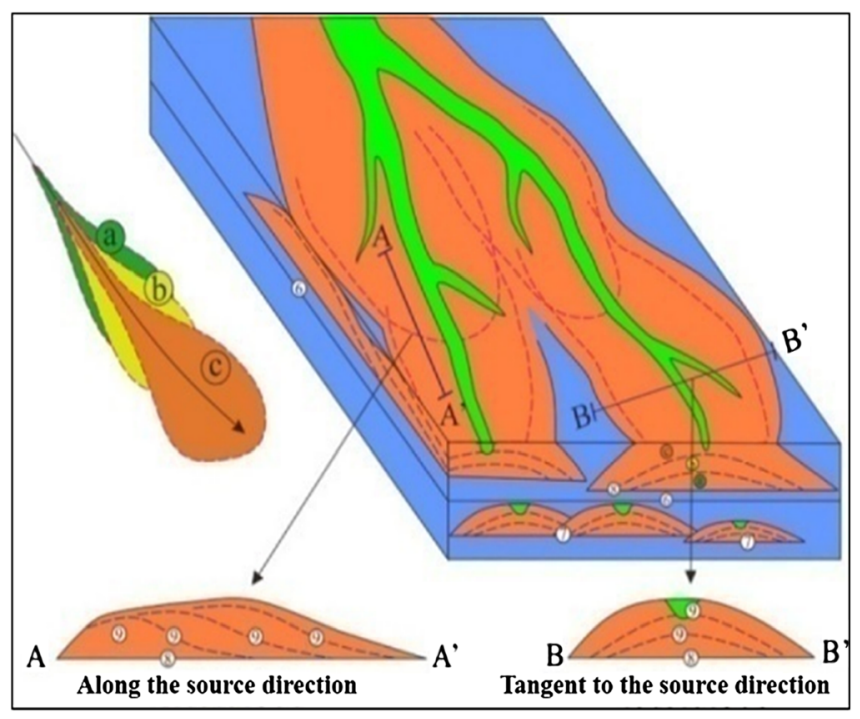

Fig. 5. Superimposed pattern and internal interlayer pattern of the mouth bar.

production showed a higher degree of connectivity and strong flooding. When the injection and production wells were not located inside the main configuration unit, i.e., in the dam edge unit, the connection between the injection and production was poor and flooding was weak.

2. The residual interlayer oil is mainly controlled by the differences in the reservoir quality of the different periods of configuration units. The injected water would preferentially enter the thicker, more permeable layer, and the poor reservoir quality sandstone would have little or no water absorption. In the production well, the residual sedimentary oil in the dam edge within the poor quality reservoir was more concentrated.

3. In addition to the influence of conventional factors, such as sedimentation rhythm and gravity, the residual oil within a layer played a key role in the formation of low-level substructures within the thick sand body. This is mainly manifested as follows: the interlayer within the layer vertically occludes the injected water, resulting in the partial presence of a weak water-flooding region with high residual oil saturation.

\subsection{Techniques for tapping the potential remaining oil based on the oil control mode configuration}

\subsubsection{The potential tapping strategy of the main thick}

During the high water-cut stage, the water-flooding trend is complex and the degree of water-flooding is not uniform, indicating different degrees of flooding in the thick oil layers and the uncertain distribution of strong flooding, which leads to a large amount of residual oil that cannot be extracted [16-18]. Presently, horizontal well technology is still gradually being developed and the cost is continuously decreasing. Compared with vertical wells, horizontal wells can more effectively tap the remaining oil and control water-flooding. Therefore, it is better to use horizontal wells in thick layers with different flooding distributions [19]. Based on the results of our configuration study, the tapping patterns of horizontal wells in different flooded sand bodies were determined for oilfield $\mathrm{A}$, including tapping the upper most remaining oil layer in the horizontal wells by means of strong bottom layer flooding, tapping the bottom most remaining oil layer in the horizontal wells by means of strong top layer flooding, and tapping the middle remaining oil layer in the horizontal wells by means of strong top and bottom layer flooding (Fig. 7).

\subsubsection{Tapping strategy of non-main thin}

Through the analysis of remaining oil, after the oilfield entered the high water-cut stage, a large amount of remaining oil was still enriched inside the dam margin facies where the thickness was thin and the physical properties were poor. Vertical wells have a small area in the production of thin-layer reservoirs, and horizontal wells have advantages in the development of thin-layer reservoirs, so horizontal wells should be used for thin-layer reservoirs [20]. Taking the E14H1 well in oilfield A as an example (Fig. 8), the well was deployed at the sand margin of the dam with a thickness of only $4 \mathrm{~m}$ and a permeability of $900 \mathrm{mD}$. After the well was put into operation, the production was quite good and the output remained at $40 \mathrm{~m}^{3} / \mathrm{d}$, while the water
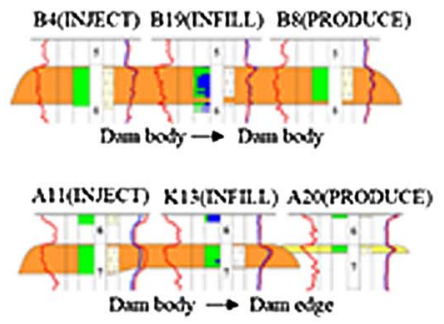

a
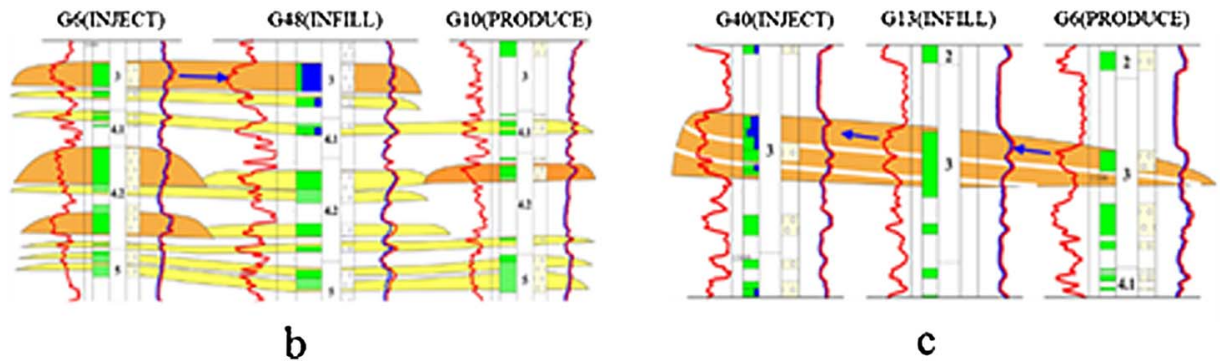

Fig. 6. Distribution of the residual oil in the high water-cut stage. a) Planar distribution of the residual oil, b) distribution of the residual oil between the layers, c) distribution of the residual interlayer oil. 


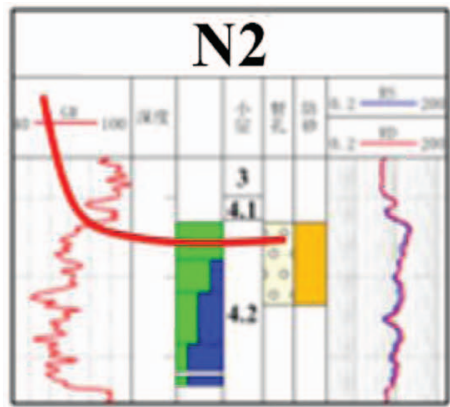

a) Top tapping

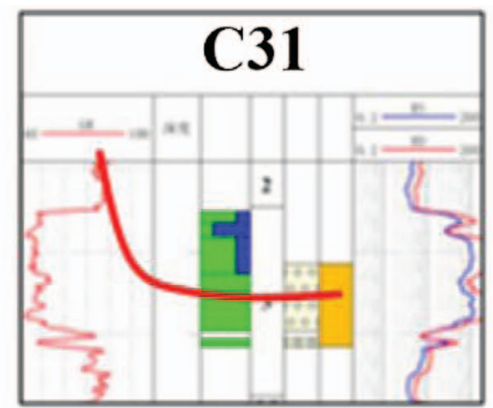

b) Bottom tapping

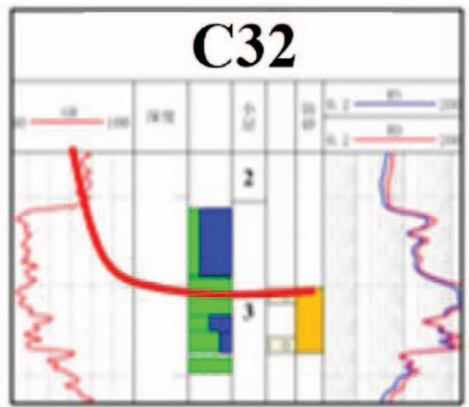

c) Middle tapping

Fig. 7. Tapping mode of horizontal wells in oilfield A. a) Top tapping, b) bottom tapping, c) middle tapping.

content was low. The successful implementation of the well proves that the development of thin layers will be a new direction for potential tapping of the remaining oil in the oilfield.

\subsubsection{Improving the adjustment strategy of well injection and production}

When the oil and water wells are located at the edge of the configuration unit, the correlation between the injection and production wells is generally poor, so the remaining oil is enriched and can be effectively tapped by means of oil-water well infilling.

Taking well N32 as an example (Fig. 9), this well is located between injection well F22 and production well F27. Before infilling, based on the fine scale characterization of this area, we conclude that this area has a strong planar heterogeneity, and the correspondence between wells F22 and F27 is poor. Thus, a large amount of the remaining oil will be enriched in well N32. The actual drilling results reveal that the well has strong water-flooding only within the contact channel of a small sub-layer, while the rest of the sand bodies, which have an initial oil production of $40 \mathrm{~m}^{3} / \mathrm{d}$ and a water content of $30 \%$, are either not flooded or experienced only small amounts of flooding. The successful application of our analytical technique to this well lays the foundation for the following tapping potential and horizontal infilling of wells with a small spacing.

\subsection{Adjustment of the tapping effect}

The tapping technology used in the adjustment of oilfield A achieved good results. From 2014 to 2016, a total of 43 horizontal wells and 28 directional wells were drilled in oilfield A to tap the remaining oil in various types of reservoirs. The actual daily production was $2829 \mathrm{~m}^{3}$. The utilization of the reserve was increased by $2890 \times 10^{4} \mathrm{~m}^{3}$ by using the injection and production well pattern.

\section{Study of the techniques for water control and oil stabilization in the high water-cut stage}

\subsection{New techniques for determining the injection} quantity for stratified injection well layers based on the quantitative characterization of the displacement

\subsubsection{Theoretical deduction of new techniques for determining the injection quantity for stratified injection well layers based on the quantitative characterization of the displacement}

During the high water-cut stage, multi-layer composite reservoirs have different levels of flooding and inter-layer

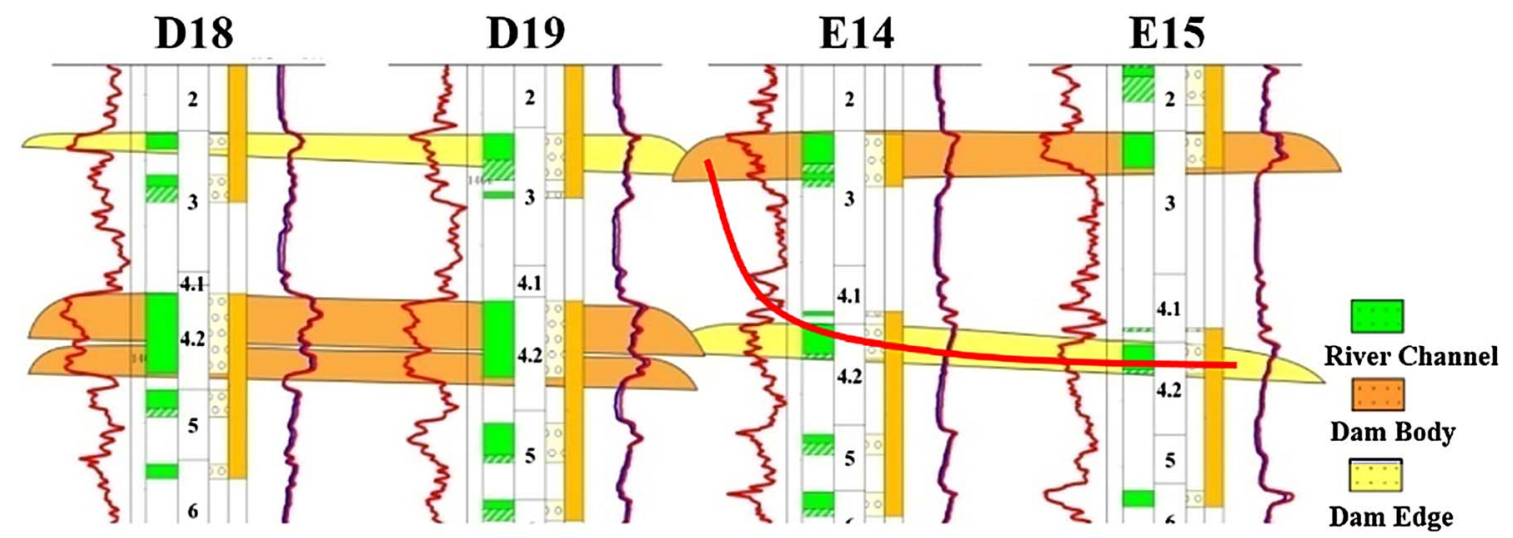

Fig. 8. Tapping practice of a thin layer in the high water-cut stage. 


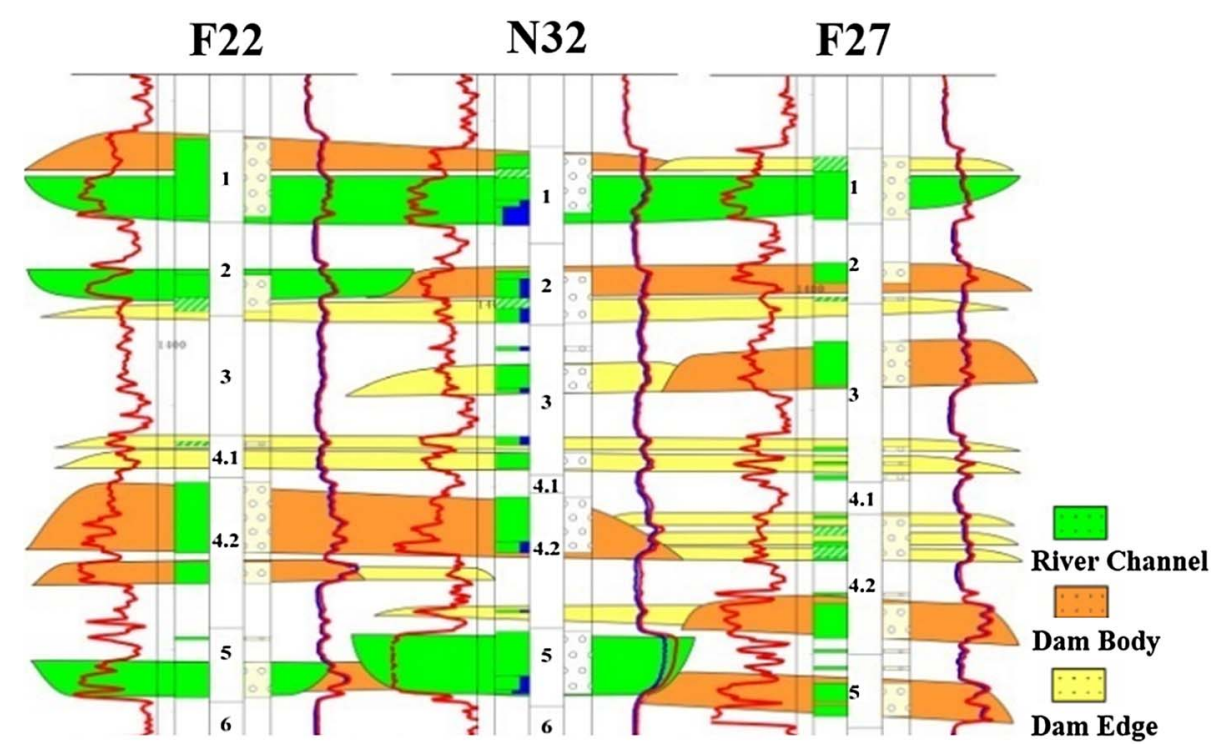

Fig. 9. Tapping of an infilled directional well during the high water-cut stage.

disturbances, which are result in an ineffective water cycle, reduced flooding efficiency, and the prominent problem of the unequal distribution of the remaining oil. Using stratified water-flooding technology, by selecting a reasonable reservoir with a small stoichiometry, a stratified injection method that takes into account the differences in the physical properties and the degree of displacement of the interlayer reservoirs has been developed [21-23].

1. New methods for the quantitative characterization of the displacement intensity.

At present, the physical quantity that characterizes the displacement intensity is $\mathrm{PV}$, i.e., the ratio of the volume of the displacing fluid to the pore volume,

$$
\mathrm{PV}=\frac{Q}{V_{\phi}},
$$

where $\mathrm{PV}$ is the PV multiple of water injected volume; $Q$ is the cumulative volume of the displacing fluid in $\mathrm{m}^{3}$; and $V_{\phi}$ is the pore volume in $\mathrm{m}^{3}$.

However, PV is not objective enough, and it is affected by the determined size of the pore volume (or grid). The smaller the pore volume (or the smaller the dividing grid), the greater the displacement is for the same flooding volume (Tab. 1).

For this reason, a new method of displacement characterization, which is not influenced by the pore volume, is proposed (Tab. 1). The parameter is defined as the ratio of the volume of the displaced fluid to the pore area of the displaced cross-section,

$$
\mathrm{PA}=\frac{Q}{A_{\phi}},
$$

where PA is the displacement flux in $\mathrm{m}$; and $A_{\phi}$ is the pore area in $\mathrm{m}^{2}$.
2. New method for determining the injection quantity for stratified injection well layers.

The principle of equilibrium displacement by injection is to deploy and adjust the injected amount in each of the layers in stratified wells to equalize the displacement intensity within a single layer. By doing this, the development of all of the levels can be balanced to minimize interlayer interference and improve the efficiency of water use and oil recovery.

Figure 10 shows a multi-layer composite reservoir with a total of $n$ long vertical sublayers. The thickness of each layer is $h_{i}$; the permeability is $K_{i}$; the porosity is $\phi_{i}$; the injection well spacing is $L$; the injection amount for the entire injection well is $q$; and the injection amount for each layer is $q_{i}$. The total cumulative water injection is $Q$, and the cumulative water injection for each layer is $Q_{i}$. The cumulative water injection can be calculated from the deployment history and the test data of the water absorption profile $i=1,2, \ldots, n-1, n$.

The displacement flux of each layer before the stratified adjustment is $\mathrm{PA}_{i}$. Assuming equilibrium displacement, given a stratified distribution, the injected quantity is optimized and adjusted. The adjustment period is $\Delta t$. After adjustment, the displacement fluxes of all of the layers are equal to $\overline{\mathrm{PA}}$, i.e.,

$$
\mathrm{PA}_{i}+\Delta \mathrm{PA}_{i}=\overline{\mathrm{PA}}
$$

where $\mathrm{PA}_{i}=\frac{Q_{i}}{A_{\phi i}}, \Delta \mathrm{PA}_{i}=\frac{q_{i} \Delta t}{A_{\phi i}}$.

The sum of the injections of all of the layers is equal to the total injection volume of the well,

$$
q=\sum_{i=1}^{n} q_{i} .
$$

Based on equations (3) and (4), the model for layered injection is, 
Table 1. Comparison between the displacement flux and the displacement volume ratio for an equally divided onedimensional displacement with different grids.

\begin{tabular}{|c|c|c|c|c|c|c|}
\hline Number of equally divided grids & 1 & 2 & $\ldots$ & $i$ & $\ldots$ & $n$ \\
\hline Pore volume & $V_{\phi}$ & $\frac{V_{\phi}}{2}$ & & $\frac{V_{\phi}}{i}$ & $\cdots$ & $\frac{V_{\phi}}{n}$ \\
\hline Displacement volume ratio & $\frac{Q}{V_{\phi}}$ & $\frac{2 Q}{V_{\phi}}$ & $\cdots$ & $\frac{i Q}{V_{\phi}}$ & $\cdots$ & $\frac{n Q}{V_{\phi}}$ \\
\hline Displacement flux & $\frac{Q}{A_{\phi}}$ & $\frac{Q}{A_{\phi}}$ & $\cdots$ & $\frac{Q}{A_{\phi}}$ & $\cdots$ & $\frac{Q}{A_{\phi}}$ \\
\hline
\end{tabular}

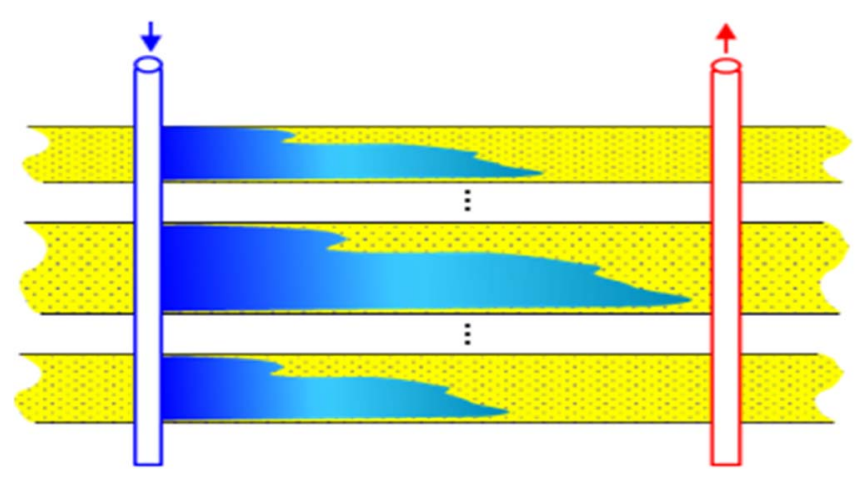

Fig. 10. Schematic diagram of multi-level oil production.

$$
\left\{\begin{array}{c}
\frac{Q_{1}}{A_{\phi 1}}+\frac{q_{1} \Delta t}{A_{\phi 1}}=\overline{\mathrm{PA}} \\
\vdots \\
\frac{Q_{i}}{A_{\phi i}}+\frac{q_{i} \Delta t}{A_{\phi i}}=\overline{\mathrm{PA}} \\
\vdots \\
\frac{Q_{n}}{A_{\phi n}}+\frac{q_{n} \Delta t}{A_{\phi n}}=\overline{\mathrm{PA}} \\
q=\sum_{i=1}^{n} q_{i} .
\end{array}\right.
$$

Solving the above model, the injection amount for each layer is,

$$
q_{k}=\frac{A_{\phi k}}{\sum_{i=1}^{n} A_{\phi i}} q+\frac{1}{\Delta t}\left(\frac{A_{\phi k}}{\sum_{i=1}^{n} A_{\phi i}} Q-Q_{k}\right) .
$$

The displacement of the cross-sectional pore area is,

$$
A_{\phi}=2 \pi R \bar{h} \bar{\phi}
$$

Equation (6) can be simplified to,

$$
q_{k}=\frac{\bar{h}_{k} \bar{\phi}_{k}}{\sum_{i=1}^{n} \bar{h}_{i} \bar{\phi}_{i}} q+\frac{1}{\Delta t}\left(\frac{\bar{h}_{k} \bar{\phi}_{k}}{\sum_{i=1}^{n} \bar{h}_{i} \bar{\phi}_{i}} Q-Q_{k}\right) .
$$

That is, the stratification coefficient of each layer in the vertical direction is,

$$
\eta_{k}=\frac{\bar{h}_{k} \bar{\phi}_{k}}{\sum_{i=1}^{n} \bar{h}_{i} \bar{\phi}_{i}}+\frac{1}{q \Delta t}\left(\frac{\bar{h}_{k} \bar{\phi}_{k}}{\sum_{i=1}^{n} \bar{h}_{i} \bar{\phi}_{i}} Q-Q_{k}\right) .
$$

As can be seen from the established calculation model for stratified injection, the stratification coefficient is mainly related to the reservoir's thickness, porosity, water-flooding history, control cycle, and injection volume. If all of the layers are in an equilibrium state of displacement, then the required quantity for each layer is proportional to the thickness of the pores. If the displacement of each layer is not uniform, but the thickness of the pores in each layer is the same, then the difference in the injection of the different layers is positively correlated with the difference in the displacement intensity of each layer and is correlated with the regulation period. The shorter the regulation period, the greater the difference in the injection amount required to achieve equilibrium displacement within each small layer.

\subsubsection{New method for determining the injection quantity in a stratified injection well based on the quantitative characterization of flooding}

Well X1 in oilfield A contains 13 small vertical layers that can be divided into four sand control sections. The well was switched to injection in April 2005. Beginning in November 2008, the thickness method was used for layer injection. In 2011, the residual oil method was used for stratified injection, and the effect of the injection gradually decreased. In October 2016, the well group had a water content of $86 \%$. To this end, we optimized the stratified injection method for well X1 and conducted a pilot stratified injection using the equilibrium displacement method.

Using the injecting conditions determined for each layer, the new method was implemented using the established injection volume. The injection volume of each small layer and the sand control section was calculated using two years as the control period (Tab. 2).

Since November 2016, a new method for stratified injection has been implemented for this well group. The watercut of the well group decreased from $86 \%$ to $72 \%$ after adjustment, and the oil production increased from $358 \mathrm{~m}^{3} / \mathrm{d}$ to $475 \mathrm{~m}^{3} / \mathrm{d}$. As of April 1, 2017, the well group had a net increase of $12241 \mathrm{~m}^{3}$ of oil and a net increase of $80.5 \mathrm{~m}^{3}$ of oil per day. The mining curve for well X1 group is shown in Figure 11. 
Table 2. Injection quantity for well X1 and each of its sublayer based on the method presented in this work.

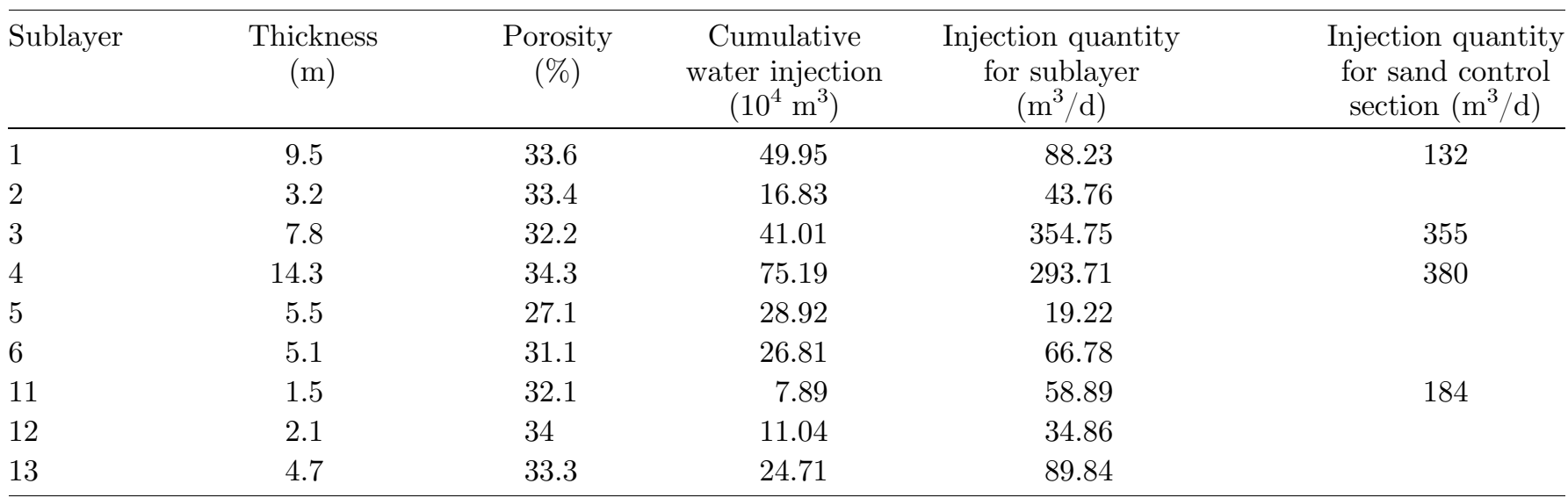

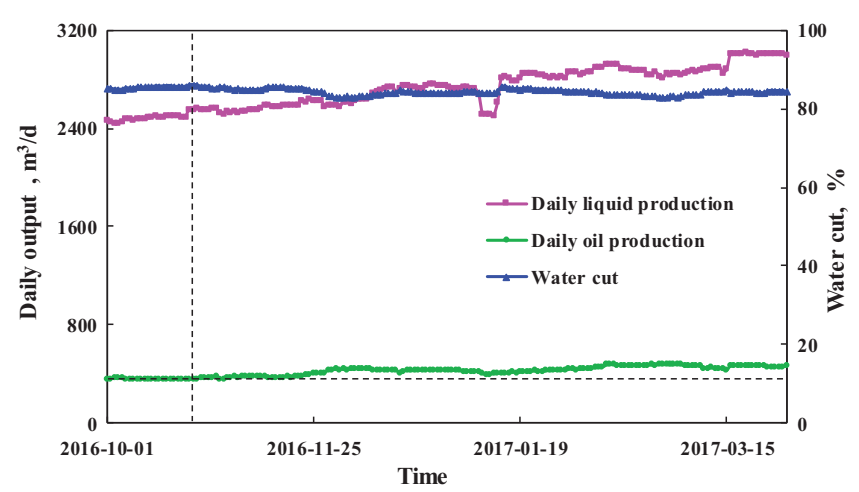

Fig. 11. Production curve for well group X.

As can be seen from Figure 9, in the current water-cut stage, the new method can specifically increase the water injection of layers that have a weak displacement intensity. The new method can also more effectively recover the residual oil, reduce the ineffective water cycle, and improve the water injection utilization rate.

\subsection{Planar alternating injection and production technology with variable intensity based on the flow field reconfiguration of the line pattern}

\subsubsection{Flow field distribution characteristics of line pattern wells in the high water-cut stage}

In order to improve oilfield development, oilfield A has used an infilling adjustment since 2009. The adjustment strategy primarily used the method of cross-well infilling, i.e., the oil well row was infilled with oil well and the water well row was infilled with water well. Through the implementation of a comprehensive adjustment, the well pattern was changed from an anti-9-point basic pattern to a line pattern of injection and production wells (Fig. 12)

A typical feature of line pattern wells is that when the row of injection wells is injected with the same injection intensity, an oil stagnation area will form in the interwell area. This residual oil stagnation area is a weak flooding site due to the pressure balanced zone, making movement of the crude oil in the reservoir difficult. In the case of equal intensity injection for all of the injection wells, the old oil wells were mainly affected by the old wells, and the new oil wells

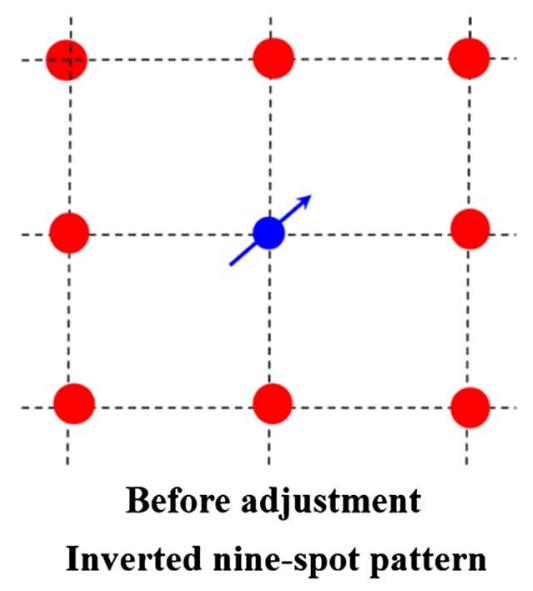

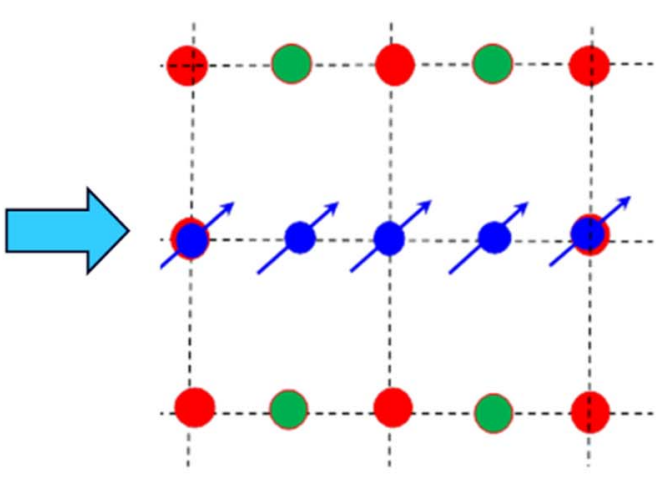

After adjustment

Row well pattern

Fig. 12. Evolution diagram of the well pattern in oilfield A. 
were mainly affected by the new wells. The effect of adjusting the wells to the remaining oil was reduced.

\subsubsection{Planar alternating injection and production technology with variable intensity based on the flow field reconfiguration of the line pattern}

The general idea of flow field reconstruction is as follows. Based on our analysis of the flow field distribution characteristics of injection and production wells, the following procedure is proposed to change the injection intensity of a water injection well. First, break the inherent pressure of the equilibrium state, and then, use the weak flooding region to reconfigure the flow field of the remaining oil, i.e., use the alternating injection technology with variable intensity along the line pattern. By changing the injection intensity between adjacent water injection wells, this technology changes the original injection and production flow lines, expands the water injection, and uses the remaining oil in the original stagnation region to improve the waterflooding effect.

After infilling oilfield A, the new and old wells alternated. Thus, there are two main methods of the alternating injection and production technology with variable intensity: increasing the water injection intensity to inject in the old wells and produce from the new wells or to inject into the new wells and produce from the old wells. Figures 13 and 14 show the flow field distribution and pressure distribution, respectively, of the line pattern of a well under injection and production with variable intensity. The dashed arrow indicates the deflection direction of the streamline.

In order to successfully implement the alternating technique with variable intensity to accurately guide the reconstruction of an oil field, the relationship between the difference in the water injection intensity and the number of streamlines with directions altered to that of the adjacent injection wells was studied. The water injection intensity difference is defined as the ratio of the water injection intensities of two adjacent wells. A quantitative study of the number of redirected streamlines and the difference in the water injection intensities was conducted to guide the allocation of the water injection volume,
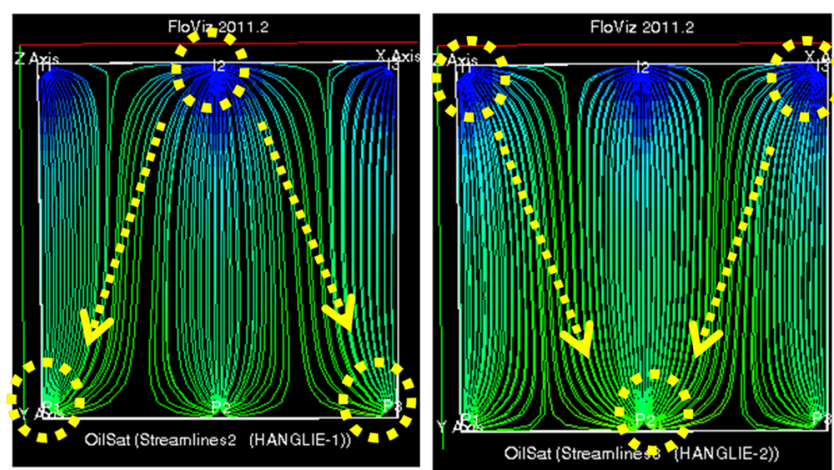

Fig. 13. Flow field distribution of a line pattern well under alternating injection and production with variable intensity.

$$
J_{\text {inj }}=\frac{I_{i}}{I_{i+1}},
$$

here, $J_{\mathrm{inj}}$ is the difference in the water injection intensities, $I_{i}$ is the water injection intensity of the i-th injection well, and $I_{i+1}$ is the water injection intensity of the $i+1$-th injection well. Based on a numerical simulation of the streamline, we conclude that the apparent deflection of the streamline can be observed when the difference in the water injection intensities in zone $\mathrm{F}$ of oilfield $\mathrm{A}$ reaches $1.25-1.50$ (Tab. 3).

\subsubsection{Application of the planar alternating injection and production technology with variable intensity based on the flow field reconfiguration of the line pattern}

Based on the results of this study, the well group containing wells F13-F17 in field F of oilfield A was selected as a case study of the application of our new method. Wells F13 and F17 are old injection wells, and wells N30 and N31 are new injection wells. Alternating injection and production with variable intensity was achieved by adjusting the intensity of adjacent oil and water wells.

By applying this technology, in the period from 2014 to 2016 , the production efficiency of this well group was

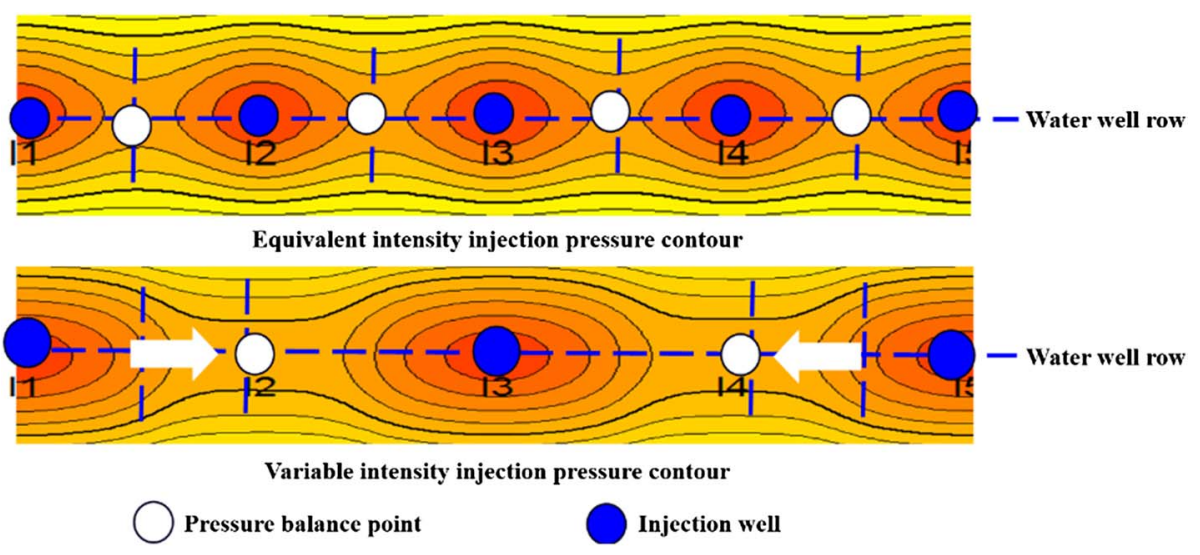

Fig. 14. Pressure field distribution of a line pattern well under alternating injection and production with variable intensity. 
Table 3. Difference in the injection intensity and the change in the streamline direction.

\begin{tabular}{lcc}
\hline $\begin{array}{l}\text { Difference in } \\
\text { injection } \\
\text { intensities }\end{array}$ & $\begin{array}{c}\text { Number of } \\
\text { redirected flow } \\
\text { pipes }\end{array}$ & $\begin{array}{c}\text { Ratio of } \\
\text { redirected flow } \\
\text { pipes (\%) }\end{array}$ \\
\hline 1.00 & 0 & 0.0 \\
1.25 & 6 & 23.1 \\
1.50 & 8 & 27.2 \\
1.75 & 10 & 30.7 \\
2.00 & 12 & 33.5 \\
\hline
\end{tabular}

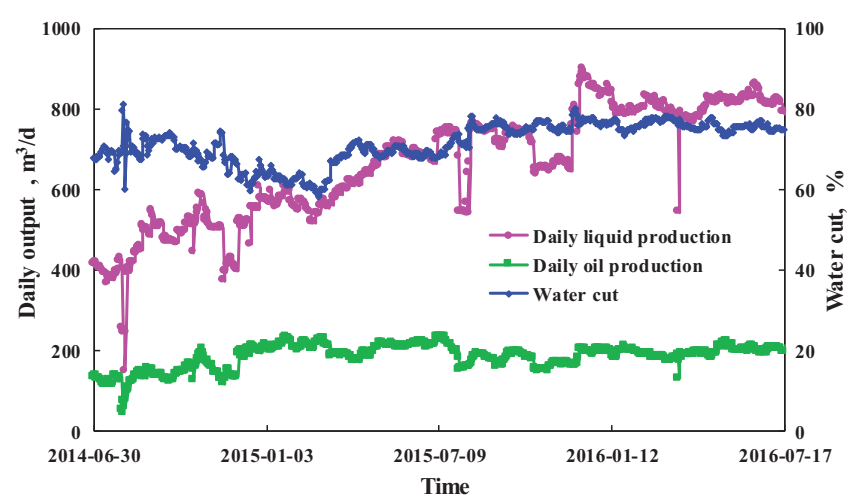

Fig. 15. Production curve for well group F13-F17.

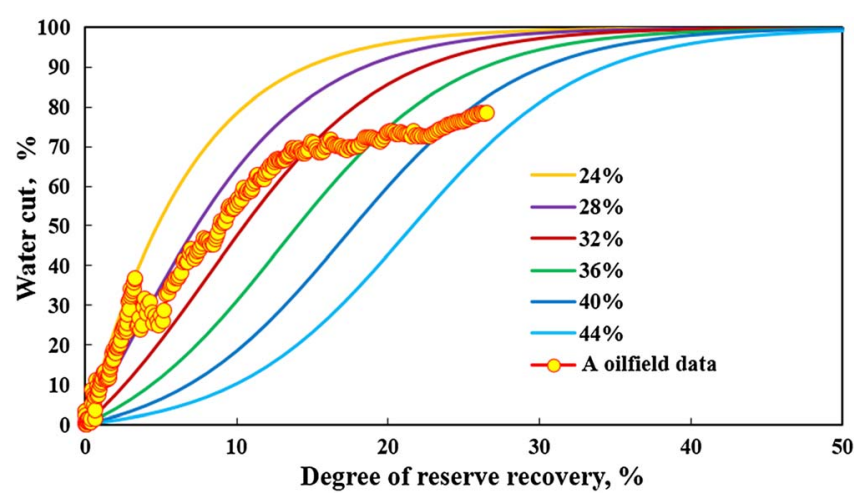

Fig. 16. Relationship between the water-cut and production of oilfield A.

significantly improved (Fig. 15). The cumulative oil yield reached $2.3 \times 10^{4} \mathrm{~m}^{3}$. Based on these results, this technology was extended and applied to the entire area of field $\mathrm{F}$ to effectively improve production. In 2016, in zone F, output decreased during the high water-cut stage.

\section{Analysis of the case study results}

By using the technology described in this paper to improve water-flooding during the high water-cut stage, the production of oilfield A continued to improve from 2014 to 2016
(Fig. 16). The increase in the water-cut rate was maintained at approximately $1 \%$, and the natural decrease in the rate was less than $9 \%$. The stable yield remained at $5.00 \times 10^{6} \mathrm{~m}^{3}$ for three consecutive years. The production increased by $1.060 \times 10^{7} \mathrm{~m}^{3}$.

\section{Conclusion}

1. Based on the detailed configuration of oil reservoirs in an offshore deltaic reservoir, the description and tapping techniques for the storage mode of the remaining oil after comprehensive adjustment of the offshore high water-cut oilfield were established.

2. Taking into consideration equilibrium displacement and using the new method of quantitative characterization by displacement, a new technique to determine the injection quantity of stratified injection wells in the high water-cut stage was established. Based on the theory of flow field strength reconfiguration, a planar alternating injection and production technology with variable intensity along the well line pattern was proposed.

3. By combining the description of the residual oil and the tapping potential technique with oil stabilization and water control technology, a set of key technical systems for improving the outcome of water-flooding in offshore high water-cut oilfields was developed. This new method provides an important reference for enhancing oil recovery, after comprehensive adjustment, in other high water-cut oil fields in the Bo Sea.

Acknowledgments. The authors acknowledge the Research on the Holographic Characterization of a Nano Porous Microcrack Coupling System in Shale Reservoirs project provided by the National Natural Science Fund of China (No. 41672132).

\section{References}

1 Zhou S.W. (2007) Effective development of offshore oilfield: Probe $\&$ practice, Petroleum Industry Publishing House, Beijing, China.

2 Zhang J.F., Luo X.B., Liu Y.X., Zhao C.M., Cu Y.C., Li Q.Z. (2011) Research on overall encryption adjustment technology of offshore oil field, Eng. Sci. 13, 5, 34-40. doi: 10.3969/j. issn.1009-1742.2011.05.006.

3 Ma K.Q., Liu Y.X., Liu Z.B., Zhou H.Y., Yang J. (2012) An analysis of the recovery-ratio evaluation method during infill and adjustment development in offshore oilfields, China Offshore Oil Gas 24, z1, 90-92. doi: 10.3969/j.issn.16731506.2012.z1.020.

4 Gladkov A., Sakhibgareev R., Salimov D., Skiba A., Drozdov O. (2017) Application of CRM for production and remaining oil reserves reservoir allocation in mature west Siberian waterflood field, in: SPE Russian Petroleum Technology Conference, 16-18 October, Moscow, Russia. Society of Petroleum Engineers. doi: 10.2118/187841-MS.

5 Zhao Y., Jiang H., Li J., Wang C., Gao Y., Yu F., Su H. (2017) Study on the classification and formation mechanism 
of microscopic remaining oil in high water cut stage based on machine learning, in: SPE Abu Dhabi International Petroleum Exhibition $\&$ Conference, 13-16 November, Abu Dhabi, UAE. Society of Petroleum Engineers. doi: 10.2118/188228MS.

6 Li J., Liu X., Gao Z., Shang B., Xu J. (2018) Reservoir architecture analysis of delta front and its control on remaining oil distribution of $\mathrm{S}$ oilfield in Bohai Bay Basin, in: SPE Asia Pacific Oil and Gas Conference and Exhibition, 23-25 October, Brisbane, Australia. Society of Petroleum Engineers. doi: 10.2118/192016-MS.

7 Roueché J.N., Karacan C.Ö. (2018) Zone identification and oil saturation prediction in a waterflooded field: Residual oil zone, East Seminole Field, Texas, USA, Permian Basin, in: SPE Improved Oil Recovery Conference, 14-18 April, Tulsa, OK. Society of Petroleum Engineers. doi: 10.2118/190170MS

8 Sayarpour M., Kabir C.S., Lake L.W. (2009) Field applications of capacitance-resistance models in waterfloods, SPE Reserv. Evalu. Eng. 12, 5, 853-864. doi: 10.2118/114983-PA.

9 Cao F., Luo H., Lake L.W. (2014) Development of a fully coupled two-phase flow based Capacitance Resistance Model (CRM), in: SPE Improved Oil Recovery Symposium, 12-16 April, Tulsa, OK. Society of Petroleum Engineers. doi: 10.2118/169485-MS.

10 Cao F., Luo H., Lake L.W. (2015) Oil-rate forecast by inferring fractional-flow models from field data with Koval method combined with the capacitance/resistance model, SPE Reserv. Evalu. Eng. 18, 4, 534-553. doi: 10.2118/ 173315-PA.

$11 \mathrm{Lu}$ X.G., Xu J. (2017) Waterflooding optimization: a pragmatic and cost-effective approach to improve oil recovery from mature fields, in: SPE/IATMI Asia Pacific Oil $\mathcal{E}$ Gas Conference and Exhibition, 17-19 October, Jakarta, Indonesia. Society of Petroleum Engineers. doi: 10.2118/ 186431-MS.

12 Zeng H., Kerans C. (2000) Amplitude versus frequencyapplications to seismic stratigraphy and reservoir characterization, part I: model, SEG Tech. Progr. Expand. Abstr. 19, 1, 8416-8421. doi: 10.1190/1.1816169.

13 Zeng H., Kerans C. (2000) Amplitude versus frequencyapplications to seismic stratigraphy and reservoir characterization, part II: Real 3-D data in Abo reservoir, Kingdom Field, West Texas, SEG Tech. Progr. Expand. Abstr. 19, 1, 8422-8427. doi: 10.1190/1.1816170.

14 Zhang X.F., Liu Z.B., Liu C., Tian B., Zhang R. (2016) Deltaic front edge reservoir configuration and its control on remaining oil distribution in $\mathrm{S}$ oilfield, Liaodong Bay depression, J. Northeast Petrol. Univ. 40, 6, 1-8. doi: 10.3969/j.issn.2095-4107.2016.06.001.
15 Liu Z.B., Hu Z.H., Ma K.Q., Liu Y.X. (2013) Research on the remaining oil distribution pattern at the mid-later development stage of commingled injection offshore oilfield, $J$. Chongqing Univ. Sci. Technol. (Nat. Sci. Ed.) 15, 4, 22-25. doi: $10.3969 /$ j.issn.1673-1980.2013.04.006.

16 Li J.F., Liu X.Q., Gao Z.N., Shang B.B., Xu J. (2018) Reservoir architecture analysis of delta front and its control on remaining oil distribution of $\mathrm{S}$ oilfield in Bohai Bay Basin, in: SPE Asia Pacific Oil $\&$ Gas Conference and Exhibition, 23-25 October, Brisbane, Australia. Society of Petroleum Engineers. doi: 10.2118/192016-MS.

17 Jiang X.Y., Wu S.H., Yu D.Y. (2007) Fluvial reservoir architecture modeling and remaining oil analysis, in: $S P E$ Annual Technical Conference and Exhibition, 11-14 November, Anaheim, CA. Society of Petroleum Engineers. doi: 10.2118/109175-MS.

18 Su Y.C., Li T.L., Huo C.L. (2015) Innovation and practice of reservoir architecture detailed characterization and remaining oil potential tapping technology in high water-cut stage of large offshore fluvial heavy oilfield, in: SPE Annual Technical Conference and Exhibition, 28-30 September, Houston, TX. Society of Petroleum Engineers. doi: 10.2118/175062-MS.

19 Leon-Ventura R., Gonzalez-G. G., Leyva-G. H. (2000) Evaluation of horizontal well production, in: SPE International Petroleum Conference and Exhibition in Mexico, 1-3 February, Villahermosa, Mexico. Society of Petroleum Engineers. doi: 10.2118/59062-MS.

20 Huo J., Shi G., Lu J., Sang L., Shi J., Tan J., Zhang Y., Fan G. (2010) The horizontal well production technique with thin bedded bottom water reservoir in Luliang oil field, in: International Oil and Gas Conference and Exhibition in China, 8-10 June, Beijing, China. Society of Petroleum Engineers. doi: 10.2118/131890-MS.

21 Jia X.F., Ma K.Q., Li Y.P., Zhou H.Y., Zhang J. (2012) Injection allocation determination method for separate injection well based on remaining oil distribution, Petrol. Drill. Tech. 40, 5, 72-76. doi: 10.3969/j.issn.10010890.2012.05.016.

22 Feng X., Wen X.H., Li B., Liu M., Zhou D.G., Ye Q.C., Huo D.M., Yang Q.H., Lan L.C. (2009) Water-injection optimization for a complex fluvial heavy-oil reservoir by integrating geological, seismic, and production data, SPE Reserv. Evalu. Eng. 12, 6. doi: 10.2118/110492-PA.

23 Liu M., Zhan S.Y., Yan W.G., Ma S.G., Yan R.C. (2014) How to make injection more effective and get production more optimum - A good case from China, in: SPE Oilfield Water Management Conference and Exhibition, 21-22 April, Kuwait City, Kuwait. Society of Petroleum Engineers. doi: 10.2118/170996-MS. 